\title{
Frege's Puzzle on the Santa Monica Beach* \\ De Jure Co-reference and the Logical Appraisal of Rational Agents
}

\section{Emiliano Boccardi}

\author{
University of Campinas \\ Department of Philosophy \\ Campinas, SP \\ Brazil \\ emiliano.boccardi@gmail.com
}

Article info

CDD: 149.946

Received: 05.10.2017; Accepted: 05.01.2018

DOI: http://dx.doi.org/10.1590/0100-6045.2018.V41N1.EB

\section{Keywords: \\ Referentialism \\ De jure co-reference \\ Frege's puzzle \\ Logical validity \\ Reasoning}

\begin{abstract}
In this paper, I argue that a number of influential Millian responses to Frege's puzzle, which consist in denying that Frege's data apply to natural languages (and thinking), are not viable if logic is to play its role in legitimizing the logical appraisal of rational subjects. A notion of validity which does justice to the normativity of logic must make room for a distinction between valid inferences and enthymemes. I discuss the prospects of formal, relevant and manifest validity as candidates for a notion which complies with this desideratum. Their success, or failure is argued to hang on the viability of a semantical account of de jure co-reference, which is in tension with standard Millian tenets. I conclude that these Millian theories face the following dilemma: either accept that there is no notion of logical validity which makes logic normative for reasoning, thus jeopardizing our well entrenched practices of rational appraisal; or accept that de jure coreference is a real semantical relation.
\end{abstract}

\footnotetext{
* The research for this paper was supported by FAPESP (grant 2014/03330-4). I wish to thank Matheus Valente Leite for our endless conversations on these issues. I am also indebted to Andrea Bianchi for his detailed and insightful comments on earlier drafts of this paper.
} 


\section{Introduction}

There is a significant difference between Frege's understanding of the role of semantics and ours. Early philosophers of language, like Frege, Russell and (the early) Wittgenstein, unlike contemporary ones, were notoriously interested in semantics primarily because they believed it could help us to free our thoughts from the ambiguities and lack of clarity of natural languages, thus enabling us to construct a perfect language, a "philosophical logic" (Russell), a "conceptual notation" (Frege); a perfect language with which mathematical concepts could be expressed unambiguously. Our present concern, on the contrary, like that of most contemporary philosophers of language, is with the significance of Frege's puzzle for the philosophy of natural language.

This shift in the proper scope of semantics had far reaching repercussions. One of them is this. Standard renderings of Frege's puzzle focused on the need to explain the informativity of identity sentences containing two co-referring expressions, while upholding to the Millian tenet that their content does not differ from that of (trivial) identity sentences containing two tokens of the same name. Since natural language expressions, unlike formal ones, do not wear their identity conditions on their sleeves, however, a lot of recent attention has been devoted to explaining, not how informative identities are possible, but rather, how trivial ones are. The challenge is that of explaining how the sheer grasp of meanings by natural speakers (and thinkers) can allow them to discern the representation of recurrent objects. Here I discuss how a solution to this problem bears on the normative role of logic in the appraisal of rational subjects.

The main question of this paper is this. How could one refashion the notion of rationality and rational explanation, in compliance with the Millian diet, so as not to yield absurd results? What notion of validity can referentialists afford, which does justice to our practices of logical appraisal? I shall argue that a necessary and sufficient condition for a notion of validity to serve this purpose is that it be discriminative, i.e. that it affords to discriminate valid from enthymematic reasoning. I proceed to show that this requirement is in tension with a strict Millian diet. Which notion of validity foots this bill?

As we shall see, the requirement that logic be normative for (natural) thinking sets constraints on the solution to Frege's puzzle.

Here is how Frege presents his data in his Über Sinn und Bedeutung (SuB):

Manuscrito-Rev. Int. Fil. Campinas, v. 41, n. 1, pp. 1-31, jan.-mar. 2018. 
(8) " $\mathrm{a}=\mathrm{a}$ " and " $\mathrm{a}=\mathrm{b}$ " are sentences of obviously different cognitive significance: (9) " $\mathrm{a}=\mathrm{a}$ " is valid a priori and according to Kant is to be called analytic, whereas sentences of the form " $\mathrm{a}=$ b" often contain very valuable extensions of our knowledge and cannot always be justified in an a priori manner.

This schematic presentation is meant to generalize the different epistemic profiles of identity sentences such as, respectively, (1) "Cicero is Cicero" where the same name is repeated twice over - and (2) "Cicero is Tully" - where two different co-referring names are used. A rational and competent speaker can understand both sentences, but assent to only one of them; moreover, one will find (2), but not (1), informative; one's non-verbal behavior may vary widely depending on which of the sentences one assents to. Following standard usage, I shall call these (alleged) facts: Frege's data.

This way of presenting the data is slightly misleading. It makes it seem like the phenomenon of triviality is confined to identity statements. This is clearly not the case. As Frege himself notices elsewhere: ${ }^{1}$

If we say 'the evening Star is a planet with a shorter period of revolution then the earth', the thought we express is other than in the sentence 'the morning Star is a planet with a shorter period of revolution than the Earth'; for somebody who does not know that the morning Star is the evening Star might regard one as true and the other as false.

The puzzling predicament is precisely to explain how those two types of sentences can differ in cognitive value (and logical import) when the expressions which feature in them are referentially indistinguishable. Frege thought that epistemic and cognitive distinctions between sentences must be reflected by their semantic structure. He thereby concluded that the connections between words and things must be mediated by the understanding, meanings reflecting different ways in which the referents of words are presented to the mind (Senses). The data, therefore, Frege thought, present a challenge to Millian theories of meaning, according to which an expression's

${ }^{1}$ Frege 1891, p. 150.

Manuscrito-Rev. Int. Fil. Campinas, v. 41, n. 1, pp. 1-31, jan.-mar. 2018. 
meaning is exhausted by its reference.

There are several ways in which philosophers of referentialist inclination have responded to this puzzle:

1. Some agree that (1) Frege's data are sound and require an explanation, and that (2) this explanation must be semantic; they argue that (3) Frege-style explanations are not viable, and they therefore think that (4) there are referentialist-friendly semantic explanations of the puzzles (Kaplan 1989, Perry 2012, Fine 2007).

2. Others, instead, while holding (3), believe that (5) Frege-style solutions are the only available semantic solutions to the puzzles, and therefore conclude that (6) the solution falls outside the scope of semantics (Kripke 1979, Wettstein 1986, Recanati 2012).

3. Others still, finally, reject (1). They think that empirical data do not support Frege's contention that true identity sentences as such can be divided in two classes, depending on their logical, cognitive or epistemic profiles (Salmon 2012, Almog 2008, Glezakos 2009).

Here I shall concentrate on the third kind of response. My aim is not to defend Frege's argument in favor of senses. Rather, I wish to defend Frege's data from the allegation that they cannot be observed in natural settings. I shall argue that an analysis of real-life inferences reveals that a proper treatment of validity must individuate expressions hyperintensionally, i.e. at a finer grain than logical equivalence does. I shall further argue that referentialist accounts of the third type above present systematic difficulties in satisfying this desideratum.

The structure of the paper is as follows. In section $2 \mathrm{I}$ argue that an adequate treatment of Frege's data requires that it be possible to devise a notion of validity that discriminates valid arguments from enthymemes (I call this feature, discriminativity). As a warm-up exercise for what follows, I show that material implication and strict validity are not discriminative in this sense. In section 3, I discuss the import of Frege's puzzle when this is considered in a natural language setting. I conjecture that the relevant phenomenon revealed by the data in these cases is that of de jure co-reference (later in the paper I show that this conjecture is correct). In section 4 I consider standard notions of formal validity vis a vis the problem of discriminativity. I argue that referentialists who do not accept sui generis de jure co-reference mischaracterize logical validity, i.e. that they lack a criterion to distinguish enthymematic from non-enthymematic valid inferences. Finally, in section 5 and 6 I argue that two notions of validity which prima facie promise to foot the referentialist bill 
(Relevant Consequence and Manifest Validity) are in fact ineffective for this purpose.

\section{Enthymematic Reasoning and Discriminativity}

Consider the following inference:

[TC]

(P1) Tully is Roman

(P2) Cicero is an orator

(C) $\exists x: x$ is a roman orator

Is TC a logically valid inference? Surely, under the intended interpretation of "Tully" and "Cicero", TC is necessarily truth preserving. Under all circumstances (of utterance or of evaluation) in which P1 and P2 are true, $\mathrm{C}$ is also true.

One could (and many would) contend, however, that there is also a sense in which TC is not logically valid, for the fact that it is necessarily truth preserving is not transparently accessible to all (rational) thinkers. According to this (formal) notion of consequence, a valid inference in the vicinity of TC is the following:

[TC*]

(P1) Tully is Roman

(P2) Cicero is an orator

(P3) Tully $=$ Cicero

(C) $\exists x: x$ is a roman orator

Arguably, the motivation behind this formality requirement stems from the observation that the validity of TC* is transparent in a way in which TC isn't. The transparency requirement, in its turn, stems from the need to apply the notion of validity in the logical appraisal of rational thinkers: if the validity of an argument is opaque to a thinker, how can we blame her for not reasoning in

Manuscrito-Rev. Int. Fil. Campinas, v. 41, n. 1, pp. 1-31, jan.-mar. 2018. 
accordance to it? TC is necessarily truth preserving in virtue of semantic properties of the premises and of the conclusion which are not necessarily epistemically transparent to someone who understands them. One who did not know that "Tully" and "Cicero" co-refer would not be in the position to see that TC is strictly valid, but he would still be able to appreciate that $\mathrm{TC}^{*}$ is, even if she had no idea about who Cicero is.

Those who know that "Tully" and "Cicero" co-refer, of course, can see that TC is strictly valid. This, however, does not render TC formally valid, not even to the eyes of the knowledgeable thinker. Rather, in this case we may describe the knowledgeable thinker as reasoning enthymematically: inferring the validity of TC with the aid of the (suppressed) premise P3, hence, indirectly, via the formal validity of TC*.

Contrast this with the following inference:

[CC]

(P1) Cicero is Roman

(P2) Cicero is an orator

(C) $\exists x: x$ is a roman orator

Prima facie, CC, like TC* and unlike TC, is transparently valid as it is. We wouldn't describe a thinker reasoning through CC as reasoning enthymematically. After all, which premise should we take her as having suppressed? Surely not:

$\left(\mathrm{P} 3^{*}\right)$ Cicero $=$ Cicero

Of course an argument obtained from CC by adding P3* as a premise - call it CC* - is also (formally) valid. But P3* appears to be redundant for the validity of CC*. One can be said to reason enthymematically only if one suppresses a premise that is indispensable to make the argument valid: one without which the argument would be invalid.

It is interesting to notice that not under all notions of logical validity is there a distinction between logically valid arguments and enthymemes. Since this point will be important in what follows, it is worth to make a digression expanding on it.

Manuscrito - Rev. Int. Fil. Campinas, v. 41, n. 1, pp. 1-31, jan.-mar. 2018. 
Consider, as an illustrative example, a notion of validity (material validity) according to which an argument is valid if and only if the corresponding material implication sentence is true. Thus, for example, according to this notion, the argument TC* above is valid in virtue of the sentence $P 1 \& P 2 \& P 3 \rightarrow C$ being true. The difficulty (vis à vis the characterization of enthymemes) arises because one can always drop a true premise from a materially valid argument, thereby obtaining another (materially) valid argument:

\section{$P 1 \& P 2 \& P 3 \rightarrow C$}

P3

\section{$P 1 \& P 2 \rightarrow C$}

Since, under this understanding, the truth of an implication sentence suffices to make the corresponding argument valid, the above theorem entails that, if TC* is materially valid, then TC is valid too, and in the very same sense. True premises are idle in contributing to the material validity of arguments, so to speak. Adding a true premise to an argument cannot "transform" a (materially) invalid argument into a valid one. Therefore, the material notion of validity makes hash of the distinction between valid arguments and enthymemes.

No one suggested that material validity should be taken to characterize the pre-theoretical notion of logical consequence, so the example above serves merely as an illustration. Many, however, (e.g. Lewis 1912) did claim that the "real" notion of logical consequence can be captured if one strengthens the material notion by requiring that the implication sentence be true at all possible worlds: $\square(P 1 \& P 2 \& P 3 \rightarrow C)$. Strict implication (as this notion is often called) appears to capture well the modal element contained in the notion of consequence. It makes plain, for example, that TC and TC* are necessarily truth preserving. Does strict validity always allow us to distinguish valid arguments from enthymemes?

Arguably not. One cannot just drop any true premise from a (strictly) valid argument and obtain another (strictly) valid argument. Premises that are only contingently true, such as P1 and P2, cannot be dropped out of TC* without disrupting the (strict) validity of the inference. This, however, is not the case if one drops a necessarily true premise. 
This is bad news for strict implication, at least for our purposes. Whether one reasons enthymematically or not does not appear to have anything to do with the modal status of the suppressed premise. Arguably, in fact, if enthymematic reasoning exists at all, it should be possible to reason enthymematically also in domains, such as arithmetic, where all the truths involved are necessary truths. If the notion of validity relevant for the logical appraisal of rational thinkers were strict validity, this would not be possible.

Worse still, given the widely shared assumption that proper names are rigid designators, identity statements like "Cicero = Tully" (P3), are all necessarily true, if they are true at all. This entails that, also in more mundane circumstances, such as those underlying inference TC above, if the notion of validity at issue were strict validity, one could not possibly reason enthymematically according to it.

I shall say that those notions of validity (and consequence) which, like material and strict validity, do not always allow us to discriminate valid from enthymematic reasoning, are non-discriminative. Here I shall argue that only a discriminative notion of validity, one which is not blind to the difference between arguments like TC and TC*, makes room for the normative role usually ascribed to logic. As we shall see, this desideratum is not easy to satisfy in a strictly referentialist framework.

Let us now go back to our main concern: the search for a discriminative notion of validity which is compatible with the tenets of referentialism. In what sense is premise $\mathrm{P}^{*}$ in $\mathrm{CC}^{*}$, unlike premise $\mathrm{P} 3$ in $\mathrm{TC} *$, redundant? It is tempting to say that P3* doesn't add anything to the validity of the inference (unlike P3), because it is trivial, and therefore logically inert. This presents the semantic theorist with a familiar predicament: how could sentences like "Tully is Cicero" and "Cicero is Cicero" differ in their logical (or epistemic) import, if they do not differ in their semantic properties, like referentialists claim? Frege's master argument against Millian theories of meaning sets off by presenting the reader precisely with these (allegedly) incontrovertible data.

\section{Frege's Puzzle in Natural Languages and De Jure Co-reference}

Are Frege's data empirically sound at all, when understood as applying to the garden variety of linguistic expressions? Almog 2008 (p. 551) thinks not: "the alleged puzzle-crisis engendered by [...] 'Frege's data' does not infest the 
natural notions of the identity-relation between objects and linguistic referenceto and thinking-about objects." Most of Almog's arguments in favor of this view stem from the observation that "informative identities pervade our discourse and thought and are as mundane as could be; indeed even cases of Frege's trouble-free " $a=a$ "-form - natural cases of natural language rather than the logic textbook - turn out to display this profile; they are informative and, at that, un-puzzling." 2

These observations, by themselves, clearly do not suffice to show that Frege's data do not have manifestations in natural settings. If anything, they only show that the typographical congruence of co-referring expressions flanking an identity sign is not a safe indicator of the sentence belonging to Frege's trouble-free " $a=a$ " form. This is old hat. It is what is exhibited, for example, by Kripke's (1979) famous Paderewski-cases, where an individual believes there to be two distinct Poles called Paderewski, one a pianist whom he met in a concert, the other a statesman, even though there is in fact just one person who is both a pianist and a statesman. This confused subject believes he has two different expressions in his vocabulary - 'Paderewski' for the pianist and 'Paderewski' for the statesman - even though they share the same spelling and reference. If he were to discover that in fact there is only one Paderewski, this would come to him as valuable new information, that is, the identity sentence flanked by those two names would be one of the logical form " $a=b$ ". This shows that the typographic criterion isn't sufficient to individuate classes of referential expressions in a way consistent with the cognitive and logical significance of the sentences which they contribute to compose, not that there is no intrinsic distinction to be made between trivial and informative identities.

Indeed, not only is typographical identity not sufficient for uninformativity (in natural settings): it can also easily be argued to be not necessary. In the sentence "Aristotle was a pupil of Plato and he was also the teacher of Alexander" the name "Aristotle" and the anaphoric pronoun "he", while differing in their typographical features, are clearly bound to co-refer (if they refer at all) by the rules of the language. ${ }^{3}$ Any sentence stating the identity of their designata would not strike a competent speaker as informative. Such a

\footnotetext{
${ }^{2}$ Ibid. p. 551.

3 While most authors agree with this contention, an argument to the contrary has been put forward in Almog, Nichols and Pepp (2015).
}

Manuscrito - Rev. Int. Fil. Campinas, v. 41, n. 1, pp. 1-31, jan.-mar. 2018. 
sentence, therefore, should count a sentence of the " $a=a$ "-type, if anything does.

These observations, as I said, however, do not suffice to prove that Frege's data are not sound in the context of natural languages. One would further need to show that there is no other intrinsic means, in the context of natural languages - other than typographical identity and difference - of distinguishing in a principled way true identity sentences of the trivial kind from those of the informative kind. Almog argues that, contrary to what Frege and most of his readers assume, we just never judge on the informativity (or uninformativity) of identity sentences based on our understanding of them alone:

informativeness lies rather in a relation between (1) the background information we have and (2) the target judgment. If the information we have resolves the truth of the judgment, it is uninformative; if not, it is informative. The informativeness is thus not intrinsic to the identity judgment. The informativeness rests in whether the in-the-head information I do have can settle the truth value of the undecided judgment. ${ }^{4}$

This alternative explanation of Frege's data certainly has some prima facie plausibility. Surely, in fact, one will be surprised to learn that two expressions co-refer if and only if one does not already know that they co-refer. Nevertheless, as we shall see, there are reasons to doubt that such differences in speaker's background knowledge capture the distinction highlighted by Frege and by those who think that the data are puzzling.

In the case of formally regimented languages, such as that of arithmetic, one may suppose that the relevant inferential distinction is produced solely by the overt distinctness of typographical form. However, as we have already said, this distinctness cannot be appealed to, in the case of natural languages. One cannot claim that the trivial sentences are those in which the same name is repeated twice; for the question immediately arises: under what conditions should two expressions count as tokens of the same name, if typographic identity is neither necessary nor sufficient for it?

Arguably, however, the difference in logical profile between sentences like "Cicero = Cicero" and "Tully = Cicero", is not primarily (or solely) due to facts

${ }^{4}$ Ibid. p. 567.

Manuscrito-Rev. Int. Fil. Campinas, v. 41, n. 1, pp. 1-31, jan.-mar. 2018. 
of typographical sameness and distinctness per se, but rather to that which sameness and distinctness of typographical form is supposed to represent, whatever that is. Or so I wish to argue. What could typographical congruence in formal languages possibly represent, at the level of rational thought, or content?

The humongous literature on Frege's puzzle has for the most part concerned itself with what accounts for the informativity of true identity sentences. While this is in keeping with Frege's own formulation of the problem, it has obscured a potentially crucial aspect of it. This paper, instead, concerns itself rather with what could explain the uninformativity of trivial identities. A proper treatment of uninformativity, or triviality, I shall argue, proves to be in tension with those responses, such as Almog's and Salmon's, which aim at dissolving Frege's puzzle.

There is a linguistic (and arguably also cognitive) phenomenon that has received a lot of attention in the recent literature, and which promises to provide us with the relevant framework for explaining triviality. This phenomenon has been given different names in the literature, including, but not limited to, "strict co-reference" (Fine 2007), "grammatically determined coreference" (Fiengo and May 2006), "explicit co-reference" (Taylor 2003), "presupposed co-reference" (Fauconnier 1974: 7-8), "internal coreference" (Lawlor 2010), "co-co-reference" (Perry 2012: 172), and "assumed coreference" (Gibbard 2012: 269-70). Other authors have dealt with this relation but didn't bother to give it a name, e.g. Campbell (1987) saw it as a relation that permits "trading on identity" between the correspondent expressions and Dickie \& Rattan (2010) followed him on that. Here I shall use the tag "de jure co-reference" (henceforth, DJCR) following the likes of Neale 2005, Pinillos 2011, Recanati 2012, and Goodsell 2014.

Intuitively, DJCR is the linguistic (and cognitive) phenomenon of representing something as the same. Fine (2007) introduces it by distinguishing cases in which something is represented as being the same - like when we say that the morning star is the evening star - and cases in which something is represented as the same - like when we say that the morning star is the morning star.

A proper treatment of same-saying (DJCR) promises to do justice to our practices of logical appraisal of speakers and thinkers. If DJCR is a real phenomenon, then this could be exploited in an explanation of the fact that all 
rational thinkers are obliged to derive the unifying conclusion in inferences like TC* and CC, but not in inferences like TC. The crucial difference is that in both TC* and CC, unlike TC, the recurrence of the same object across the premises is transparent. The data point in the direction of a transparent notion of validity which would comply with the desideratum that dropping assumption $\mathrm{P} 3$ in TC* makes the inference invalid (in the relevant sense). ${ }^{5}$ Such notion of validity would thereby explain in what sense, if a speaker (or thinker) derives the unifying conclusion in TC, she is reasoning enthymematically.

Over the past few decades, it has become common sense, among philosophers, to recognize that the contents of our thoughts and language expressions are to be individuated (in part) by some external factors not transparently accessible to thinkers and speakers. This has put some strain on the classical understanding of logical validity as guaranteed truth preservation. For it is no longer clear what could possibly "guarantee" truth preservation, given that thinkers cannot be held entirely accountable for the identity (or difference) of their own thoughts. Familiar cases of switching, where, due to a change in the relevant external factors, unbeknownst to a thinker, an apparently valid inference commits the fallacy of equivocation, for example, prompted some to conceive of logical validity as being world-involving and nontransparent.

Although such externalist understandings of validity (such as the material and strict notions discussed in the introduction) are unobjectionable for certain purposes, in the context of this analysis the notion of validity which matters is one to do with the rational justifications that thinkers and speakers may have for counting an argument as valid. These considerations are well expressed in this passage by Boghossian (1994: 39-40):

we [...] ascribe thoughts to a person [...] for two related purposes; on the one hand, to enable assessments of his rationality and, on the other, to explain his behavior. As these matters are currently conceived, a thought must be epistemically transparent if it is to play these roles. Without transparency, our conceptions of rationality and rational explanation yield absurd results. We manifest recognition of this fact by barring de re thoughts -

\footnotetext{
5 In our terminology, the requirement that Frege's data seem to impose on validity is that it be discriminative.
}

Manuscrito - Rev. Int. Fil. Campinas, v. 41, n. 1, pp. 1-31, jan.-mar. 2018. 
thoughts which intuitively lack epistemic transparency - from figuring in assessments of rationality and psychological explanation. However, if we abandon transparency even for de dicto thoughts, and hence in effect altogether, then we must either jettison the notion of rationality and with it the practice of psychological explanation that it underwrites, or we must show these notions can be refashioned so as not to yield absurd results.

The main question of this paper is this. How could one refashion the notion of rationality and rational explanation, in compliance with the Millian diet, so as not to yield absurd results? What notion of validity can referentialists afford, which does justice to our practices of logical appraisal? I have argued that a necessary and sufficient condition for a notion of validity to serve this purpose is that it be discriminative, i.e. that it affords to discriminate valid from enthymematic reasoning. Which notion of validity foots this bill?

\section{Formal Validity and Same-saying}

The most promising place to look for an answer to this question is of course the notion of formal validity. As MacFarlane (2004: 21) aptly put it: "we require logical validity to be formal because we require it to be transparent, and we require it to be transparent because of the reasons and responsibilities to which it gives rise."

Before discussing the notion of formal validity in more details, it is worth noting that what we are after is a garden variety of this notion, one which someone who's not a logician may be reasonably argued to deploy. Dictionary entries define logical consequence in terms of the conclusion "following" from the premises according to the criteria of "correct", or "valid" reasoning. In standard logic textbooks and academic articles, instead, the notion of validity is usually defined in more abstract, less intuitive terms. An argument expressed in a formal system $\mathrm{K}$ is "syntactically valid" if and only if it can be proved (relative to $\mathrm{K}$ ) that the conclusion "follows" from the premises. And an argument is "semantically valid" if and only if, given a rigorously specified interpretation of the logical vocabulary, no assignment of values to the non-logical vocabulary (an "interpretation"), makes the premises true and the conclusion false.

Formal systems, in this sense, are rigorously constrained sets of uninterpreted

Manuscrito - Rev. Int. Fil. Campinas, v. 41, n. 1, pp. 1-31, jan.-mar. 2018. 
strings of symbols constructed from artificially fixed alphabets. Some of these symbols - those belonging to the so called "logical vocabulary" - evoke words of natural languages. Thus, for example, the symbols $\exists, \&, \forall$, or $\rightarrow$ evoke the natural language expressions "exists", "and", "for all", and "implies"; the other terms that feature in formal systems are schematic letters meant to mimic the behavior of arbitrary non-logical names, predicates or functions. Crucially, the non-logical terms in a formal system are not referring expressions. As a consequence, the logical vocabulary also should not be taken to be the same as the logical vocabulary in natural languages, but only a formal shadow of it. I shall call a notion of validity definable in these terms: "logic textbook validity". Because of how it is defined, logic textbook validity is ill suited for our purposes. As Almog correctly observes:

if Frege were to say: " $a=a$ " is provable but " $a=b$ " is not, therein lies the difference he'd be edging closer to dissolving the puzzle altogether. For he would now not try to assign to each of " $a=a$ " and " $\mathrm{a}=\mathrm{b}$ " its own distinct intrinsic interpreted-object (meaning, proposition, thought, etc.) and expect that within that interpretedobject lies the solution. He'd rather tell us, as we tell our Logic students, that provability is a relation between axioms (assumptions, data bases, etc.) and the target sentence - relative to this set of axioms (assumptions, etc.), so and so is provable; not so, relative to another axiom-set. [...] " $\mathrm{a}=\mathrm{a}$ " and " $\mathrm{a}=\mathrm{b}$ " are not sentences encountered outside a logic (or algebra or group theory etc.) textbook; no one on the Santa Monica Beach or on CNN asserts the schematic sentence " $a=b$ ". ${ }^{6}$

Almog continues to argue that:

If we are to have genuine data, we need to isolate a duo of interpreted sentences (of the required form). And so, as I will understand Frege's ground-zero data, he can say [...] that "this = this" (in a given context) or "Paderewski $=$ Paderewski" or "The author of On Denoting = the author of On Denoting" are true and not informative but "this = that", "Paderewski = Mylcesky"

${ }^{6}$ Almog 2007: 553.

Manuscrito - Rev. Int. Fil. Campinas, v. 41, n. 1, pp. 1-31, jan.-mar. 2018. 
and "The author of [On Denoting] is the author of Marriage and Morals" are true but informative. ${ }^{7}$

After briefly considering (hence implicitly conceding) the possibility that the notion of formal validity might rescue the cogency of Frege's data, Almog quickly dismisses it on the grounds that logic textbook validity (LT-validity for short) is defined over uninterpreted symbolic systems. ${ }^{8}$ But this - and the pun is not intended but rather appropriate - would be a valid argument only if it could be shown that there is no other, more mundane, garden variety of logical consequence, which one might reasonably exploit to the rescue of Frege's data.

As I shall argue, not only does such a mundane notion of logical consequence - one which might arguably well be used on the Santa Monica beach - exists; but it is also the case that any logic textbook notion of logical consequence is answerable to such Santa Monica Beach notion (SM-validity). In other words, I argue that if it wasn't because LT-consequence conforms to SMconsequence, the whole enterprise of formal logic would be devoid of any epistemic or rational value.

Almog, I think, is getting the explanatory relation between the formalized notion of entailment, and the mundane, Santa Monica Beach variety of entailment upside down. True, in logic textbooks we are told that an argument is valid iff it is a replacement instance of a given abstract schematic form. This may convey the misguided impression that it is the schematic notion of validity which wears the conceptual trousers, when it comes to understanding what makes for a valid argument. But this is fantastic! As Almog's rightly points out, uninterpreted schemata are just not the right sort of entities of which one might reasonably ask whether they are "valid", or "true" in any literal sense.

The abstract schemata are "valid" only in a derivative sense. The primitive notion is that of a SM-valid argument, while LT-validity only reflects the results of the millennial, ongoing quest for the formal essence of real life valid arguments. It is the abstract schemata that are answerable to real life inferences, not viceversa. Of course, if schemata reliably capture simple SM-inferences,

\footnotetext{
${ }^{7}$ Ibid. p. 555.

${ }^{8}$ It should be noted that this manoeuvre must be understood as purely illustrative, and not representative of the historical Frege. Frege does not operate with uninterpreted symbols. The sentences in his writings are not schematic, but contentful claims about natural numbers.
}

Manuscrito - Rev. Int. Fil. Campinas, v. 41, n. 1, pp. 1-31, jan.-mar. 2018. 
then they might be used to argue that a real life argument is invalid. But this is only a result of the fact that our cognitive capacity to detect validity in real life scenarios is subject to various severe limitations. Formal logic as we know it was developed in an attempt to capture all and only the valid arguments that mathematicians deploy in their reasoning.

The normative use of LT-validity kicks in at a later stage, as a means of sidestepping the cognitive limitations of our minds, and only after their adequacy vis à vis SM-validities has been established, or assumed. As Shapiro (2005, p. 669) puts it:

neither proof-theoretic consequence nor model-theoretic consequence [LT-consequence, in our terminology] is primary. Instead, they illuminate the various informal, pre-theoretic notions of logical consequence.

How should we characterize the informal notion of formal validity? There is a long-standing tradition according to which logical validity should be a matter of "form". Indeed, the Logic Textbook notion of "model-theoretic consequence" is arguably meant to capture the essence of some more mundane notion of formal entailment, to which it is answerable (cf. Shapiro 2005, p. 663).

Most treatments of a formal notion of consequence start by establishing a distinction between the logical and the non-logical part of the vocabulary. The "logical vocabulary" typically comprises: truth-functional connectives ("not", "and", "or", "if ... then"), quantifiers ("some", "all"), and a sign for identity. There is a vast literature as to how we should divide terms into logical and nonlogical ones in a principled way, and there is nothing like an agreement as to how this should be done. However, for our purposes, we don't need to delve into the details of these proposals: following Shapiro (and many other authors), we shall here just take the logical vocabulary as given.

Intuitively, the notion of formal validity is then given as follows: an argument is formally valid if and only if the truth of the premises guarantees the truth of the conclusion in virtue of the meanings of the logical terminology. How is one to know that the truth of the conclusion follows solely in virtue of the meaning of the logical vocabulary? What is the meaning of the logical vocabulary anyway? Usually, the semantic contribution of logical terms is provided implicitly, by describing their truth-functional behavior. This appears to make our characterization of formal validity idle from an operational point 
of view.

Quine (1953: 22-23) characterizes formal consequence in the following terms:

If we suppose a prior inventory of logical particles, comprising "no", "un-", "not", "if", "then", "and", etc., then in general a logical truth is a statement which is true and remains true under all reinterpretations of its components other than the logical particles.

He also claims (1950: xv) that "reinterpreting" here means "making substitutions as we please upon its component words and phrase" (my emphasis). As Strawson noticed (1957: 15), however, we can't take Quine too seriously at that:

For suppose we take an example of an undoubted logical truth say, "If Socrates is wise, then Socrates is wise". We might be pleased to replace the phrase "Socrates is wise" in its second occurrence with the phrase "Plato is foolish", while leaving it untouched in its first occurrence. But few people would want to say that "If Socrates is wise, then Plato is foolish" expressed a truth of any kind; and fewer still would want to say that the fact that it was obtainable by means of this kind of substitution from "If Socrates is wise, then Socrates is wise", showed that the latter did not, after all, express a logical truth.

Now, how should a rational reasoner know when two substitutions are the same and when not? Notice that one cannot answer to this question by saying: "when the two tokens being substituted share the same sense", for one would thereby beg the question against someone (like Almog) who denies that there are such things as senses. At any rate, one could not give such an answer if Frege's data are to be used in an argument in favor of the very existence of senses. As Glezakos noted:

The puzzle is posed in terms of sentence form, and that sentence form is determined by the identity or distinctness of the names 
appearing in the sentence. If a name is in part individuated by the Sinn associated with it, then, in order to be puzzled, one would need to be committed to Sinne and their role in determining name identity. If we are not so committed, we will find that the puzzle has no hold of us. ${ }^{9}$

Notice, however, that one can neither answer to that question by saying: "when the two terms are typographically identical". We have already discussed at length the obvious shortcomings of such a strategy in natural settings. More importantly, though, one cannot answer to the question - as Almog and Quine are asking us to do - by saying: "when the two terms being substituted corefer". Such an answer, in fact, would unduly expand the class of logical truths. Formal consequence, under this interpretation, would be coextensive with strict consequence. Notice that, just like what happens in the case of Strict Validity, Formal Validity, so interpreted, makes hash of the distinction between enthymematically valid arguments and valid arguments simpliciter: in our terminology, it is non discriminative.

If it is formal validity that underwrites the relevant notion of consequence, then Almog would not (and could not) be claiming that, when the agent's background knowledge settles the truth of the identity statement, she reasons enthymematically, by assuming implicitly the suppressed identity premise (which would presuppose that the unadorned argument is not formally valid as it is). Rather, according to this reading, Almog would have to claim that, in these cases, the unifying argument is just plain (formally) valid, unadorned as it is. If so, unless we follow Fine and his likes in insisting that there are linguistic and cognitive means of representing same-saying, and unless these means feature essentially in our reasoning practices, the notion of formal validity is just going to re-propose the same predicament in which we found ourselves when we considered strict validity.

These considerations invite us to express the familiar predicament posed by Frege's puzzle in a particularly cogent fashion. Consider the following example. Lois Lane both believes that Superman can fly and that Clark Kent cannot fly. If Referentialism is true, the content of her beliefs is an outright contradiction. Standard presentations of the predicament ask how the referentialist can accommodate for the fact that, in these circumstances, we don't normally

${ }^{9}$ Glezakos 2009, p. 206.

Manuscrito - Rev. Int. Fil. Campinas, v. 41, n. 1, pp. 1-31, jan.-mar. 2018. 
charge Lois of being irrational. She is ignorant of some facts, we think, rather than lacking logical acumen. The analysis presented here allows us to put more pressure on this question. We are not only requiring an explanation for why we don't think Lois is believing the impossible. We are claiming, further, that Lois should know better, lest she be charged with lacking knowledge of logical facts. Frege's puzzle can then be seen as forcing the referentialist to account for logical consequence in a way that is discriminative in the relevant sense. I argue that this desideratum can be met only if one concedes that de jure co-reference is a genuine semantic phenomenon.

Notice that the argument here is not (merely) that referentialists who do not accept sui generis de jure co-reference will have problems characterising logical validity, i.e. that they lack a criterion to distinguish enthymematic from nonenthymematic inferences. The argument, rather, is that such referentialists are at variance with the criterion that there in fact is, i.e. that they falsely classify our real-life natural-language inferences. An analysis of real-life inferences, we have seen, reveals that a proper treatment of validity must individuate sentences hyperintensionally. I have further argued that hard referentialist accounts, such as Salmon's, Almog's and Glezakos' present systematic difficulties in satisfying this desideratum. If these difficulties proved to be insurmountable, these accounts will have to be abandoned in their present form.

The rest of this paper is devoted to considering two alternative notions of consequence and validity, which promise to provide the referentialist with a discriminative notion of validity: (1) Anderson and Belnap's Relevant Consequence and (2) Fine's Manifest Validity. I shall argue that they both fail. ${ }^{10}$

\section{Relevant consequence}

In their Enthymemes (1961), Anderson and Belnap claim that the need to distinguish plain valid arguments from enthymemes can be met if we adopt a (relevantist) notion of consequence, regulated by their system E. While the details of their argument and of the system need not concern us here, it is interesting to notice that, even adopting relevant entailment as the base notion

\footnotetext{
${ }^{10}$ Notice that what I shall argue for is not that there is some intrinsic deficiency in these treatments of validity, but only that they are of no avail to the referentialist accounts under consideration.
}

Manuscrito - Rev. Int. Fil. Campinas, v. 41, n. 1, pp. 1-31, jan.-mar. 2018. 
of consequence, far from affording the referentialist with an easy way out of Frege's puzzle without the idea that de jure co-reference should be given a semantic account, Anderson and Belnap's treatment seems to command it.

Like all relevant notions of consequence, in fact, theirs has it that, "as a minimal requirement for relevance of A to B (in propositional logic), it seems reasonable to demand that if $A \rightarrow B$ is accepted, then $\mathrm{A}$ and $\mathrm{B}$ should share a propositional variable". ${ }^{11}$ By a reasoning which should be familiar by now, it can be argued that, if the notion of relevant consequence is to be discriminative (as they claim it is), this requires that such "sharing" be understood as a semantical affair. Anderson and Belnap appear to agree with this: "the variablesharing condition $[\ldots]$ is semantical in character, since it has to do with possible assignments of values to the propositional variables". ${ }^{12}$

\section{Manifest Validity}

In his monograph Semantic Relationism (henceforth SR), Kit Fine argues that the solution to Frege's puzzle requires that we think of the domain of semantics as closed under what he calls "manifest consequence", rather than under classical consequence. The notion is devised to capture those inferences (and only those) which speakers and thinkers may be held accountable for. Since this notion of validity purports to take our bull (transparency) by the horns, it is worth to delve a little more into its details.

Fine provides two analyses of this notion. The first one (SR, 48) is meant to capture the intuition that inferences such as TC are opaque (non manifest) because they essentially depend on the recurrence of the same object in the premises. The ensuing notion tries to capture the idea that the manifest consequences are only those which "survive" when we replace all reoccurrences of the same object in the hypotheses with occurrences of different objects (Fine calls this a "differentiation" of the hypotheses).

The second one (SR, 55ff, 136n14), on which I shall concentrate here, is based on the idea that same-saying (DJCR) ought be accounted for in terms of some kind of "coordination" between the meanings of the expressions. This is roughly how the idea is supposed to work. Given a sequence of propositions

11 Anderson and Belnap 1961: 718. My emphasis.

12 Anderson and Belnap 1962: 49.

Manuscrito - Rev. Int. Fil. Campinas, v. 41, n. 1, pp. 1-31, jan.-mar. 2018. 
(or contents) $P=p_{1}, p_{2}, \ldots p_{n}$, a "coordination scheme" is an equivalence relation $\mathrm{C}$ such that any two occurrences of individuals featuring in $p_{1}, p_{2}, \ldots p_{n}$ are related by $\mathrm{C}$ only if they are occurrences of the same individual. An argument $\mathrm{A}$ from $p_{1}, p_{2}, \ldots p_{n}$ to $\mathrm{q}$, will be said to be valid relative to the coordination scheme $\mathrm{C}$ if the argument obtained by replacing in $\mathrm{A}$ each individual for its equivalence class under $C$ is (classically) valid. Thus, for example, the propositions $\mathrm{p}_{1}=$ Cicero is Roman and $\mathrm{p}_{2}=$ Cicero is an orator can be coordinated in two different ways, one, $\mathrm{C}^{+}$, in which the two occurrences of Cicero are positively coordinated (the token expressions corresponding to them are de jure co-referential), and one, $\mathrm{C}^{-}$, in which they are negatively coordinated. Thus, an argument from $p_{1}, p_{2}$ to $\exists x: x$ is a roman orator will be valid relative to $\mathrm{C}^{+}$ (this is the case of argument CC above) and not valid relative to $\mathrm{C}^{-}$(this is the case of argument TC). An argument from $p_{1}, p_{2}, \ldots p_{n}$ to $\mathrm{q}$ will be said to be manifestly valid if, for any coordination scheme $\mathrm{C}$ on $p_{1}, p_{2}, \ldots p_{n}$, there is an extension $C^{\prime}$ of it to $p_{1}, p_{2}, \ldots p_{n}, q$ such that the argument from $p_{1}, p_{2}, \ldots p_{n}$ to $\mathrm{q}$ is valid under $\mathrm{C}^{\prime}$. In a nutshell, under this second analysis, an argument is manifestly valid if it is valid under all possible coordination schemes. ${ }^{13}$

How does manifest validity score, when it comes to discriminativity? Can a manifestly invalid argument be rendered manifestly valid by adding a unifying premise? Notice that, under the above characterization, neither TC nor CC turn out to be (manifestly) valid arguments. Thus, so unadorned, manifest validity also does hash of the distinctions which make for enthymematic reasoning, at least in those circumstances. Indeed, in his critical essay on SR, Salmon (2012, n.25, 227) exploited this fact to argue that Fine's semantic relationism suffers from the same problem that, according to Fine, standard Millianism suffers from. However, as Fine notices in his rejoinder (Fine 2014, n.2, 426), the characterization of manifest consequence presented above is meant to apply only to the case of uncoordinated propositions: "if extended to coordinated propositions, then it must be done in such a way that $F \& G(x)$ will be a manifest consequence of $\mathrm{F}(\mathrm{x})$ and $\mathrm{G}(\mathrm{x})$ when the two $\mathrm{x}$ 's in the premisses are coordinated". Manifest validity, when not adorned by coordination axioms

\footnotetext{
13 The first characterization, the one based on the notion of differentiation, has been argued to be subject to counterexamples (see Salmon 2012 and Fine 2014). However, it has been shown to be amendable to yield the desired results, and (once amended) to be equivalent to the characterization based on coordination (Weiss 2014).
}

Manuscrito - Rev. Int. Fil. Campinas, v. 41, n. 1, pp. 1-31, jan.-mar. 2018. 
tracking recurrences (and lack of recurrences), represents the viewpoint of a thinker (speaker) whose singular terms are all uncoordinated.

This will be crucial for our purposes, for it exposes the main concern of this paper in a very concise way. If there exists no semantic coordination between token expressions that is transparent, like the hard referentialist thinks, then all propositions will be uncoordinated. If things are so, then transparent validity (i.e. manifest validity) will not be discriminative, and hence, I argue, it will not afford a normative role for logic in reasoning (not at least in cases of reasoning like $\mathrm{CC}$ and $\left.\mathrm{CT}^{*}\right)$.

\section{Valid Reasoning in an Uncoordinated World}

Bearing all this in mind, let us go back to our assessment of the storm-in-atea-cup response to the puzzle. Almog and his followers have claimed that only presupposing that trivial identity statements differ in meaning from informative ones, can one find anything puzzling about Frege's data. If we give up on this stubborn preconception, they think, then Frege's puzzle will be seen to disappear:

Some, e.g. David Kaplan in conversation and in lectures called "Word and Belief", take [Frege's data] to show that "Paderewski = Paderewski" is "really" (visible grammar aside) of the "a = b" form - what you see in the grammar of our simple English sentence is not what you logically get. [...] If so, I don't know of any natural language example that is of the " $a=a$ " form [...]. If no sentences of ordinary language ever have the " $a=a$ " form, what was Frege worried about? ${ }^{14}$

Here is what I think is wrong with this attempt at dissolving the puzzle. Suppose that, when reasoning, we were never able to directly trade on the coreference of two terms of ordinary language (without the further assumption that they do co-refer). According to this hypothesis, same-saying, or de jure coreference, is not a real phenomenon. What sameness and distinctness of visible grammar convey (in formal languages) is not any fact at the level of the

14 Almog 2008, p. 572.

Manuscrito - Rev. Int. Fil. Campinas, v. 41, n. 1, pp. 1-31, jan.-mar. 2018. 
contents expressed. If two expressions co-refer, under this hypothesis, they corefer merely de facto. If things are so, sequences of propositions are never coordinated in Fine's sense, hence, as I have argued, the notion of validity will not be suitably discriminative. It is easy to see that this conclusion is unwanted. Consider again the inference CC. An appropriate rendering of it in a world without coordination is the following, where superscripts serve to differentiate between the (uncoordinated) tokens:

[CC Almog]

(P1) Cicero $^{1}$ is Roman

(P2) Cicero $^{2}$ is an orator

(C) $\exists x: x$ is a roman orator

Because the occurrences of Cicero corresponding to Cicero ${ }^{1}$ and $\mathrm{Cicero}^{2}$ are not coordinated, someone reasoning along these lines must be doing so on the further assumption that they do co-refer. This fact, however, cannot be expressed by appending the further disambiguating premise Cicero $^{1}=$ Cicero $^{2}$. Superscripts, we said, track expression tokens, not types: different tokens, different superscripts. Since the superscripts 1 and 2 have already been "used up", the inference should be represented as follows:

[Regress]

(P1) Cicero ${ }^{1}$ is Roman

(P2) $\mathrm{CicerO}^{2}$ is an orator

$\left(\mathrm{P}^{* *}\right) \mathrm{Cicero}^{3}=$ Cicero $^{4}$

(C) $\exists x: x$ is a roman orator

This is clearly problematic, since for each new premise one is going to need 
further ones to represent the relevant facts of co-reference. ${ }^{15}$ It should be clear that this regress is vicious, since one never seems to reach a point where the argument is manifestly valid. ${ }^{16}$ And if an argument is not manifestly valid, we have seen, an agent cannot be blamed for not reasoning in accordance with it.

It will be objected that I am here misinterpreting Almog. Perhaps, what Almog is suggesting is not that the inference CC is enthymematic, i.e. that it suppresses the indispensable premise Cicero $^{1}=$ Cicero $^{2}$. Perhaps what the knowledgeable reasoner possesses (and the ignorant one lacks) is the metalinguistic information that the first two tokens co-refer. Thus, the actual (non-enthymematic) reasoning should rather be represented as:

[Metalinguistic CC]

(P1) Cicero ${ }^{1}$ is Roman

(P2) Cicero $^{2}$ is an orator

(P3***) "Cicero" " co-refers with "Cicero2"

(C) $\exists x: x$ is a roman orator

This interpretation is in keeping with a number of influential responses to Frege's puzzle. For example, with Salmon's:

To be sure $\lceil a=b\rceil$ sounds informative, whereas $\lceil a=a\rceil$ does not. Indeed, an utterance of $\lceil a=b\rceil$ genuinely imparts information that is more valuable than that imparted by an utterance of $\lceil a=a\rceil$. For example, it imparts the non-trivial linguistic information about the sentence $[a=b]$ that it is true, and hence that the names $\mathrm{a}$ and $\mathrm{b}$ are co-referential. But this is pragmatically imparted information. (Salmon 1986, 78-79, original emphasis)

Now, this response can be argued to be problematic for a number of

15 Cf. Campbell 1987 for a similar regress argument.

16 This is a consequence of the fact that manifest validity is non discriminative (if it is not relativised to coordination schemes).

Manuscrito - Rev. Int. Fil. Campinas, v. 41, n. 1, pp. 1-31, jan.-mar. 2018. 
reasons. Firstly, as noted by Fine (SR, p. 81), "there is something quite bizarre about the idea that, in drawing out the logical consequences of a given set of propositions, it should be necessary to reason explicitly about the language by which the propositions are expressed". Secondly, metalinguistic CC is arguably a different argument from CC, and an explanation of the validity of the latter which does not allow us to distinguish them would be unsatisfactory, even if for this reason alone. Worse still, for our concerns, metalinguistic CC is not a manifestly valid argument, unless something exists which secures the coordination between the names that feature in proposition P3*** with those used to express propositions P1 and P2. As Salmon puts it (voicing Fine's objection, that he wishes to rebuke): "instead of reducing recurrence, correlating information merely introduces more recurrence, which must now be semantically coordinated as well." [Salmon 2012: 423]

The reader must not be tricked by the fact that the argument appears to be obviously valid. Of course it appears valid, because it is valid! But here we are precisely in the business of asking in virtue of what (and according to what notion) it is valid. Since in a world where coordination schemes did not exist at the level of content, metalinguistic CC would not be a manifestly valid argument, one is left wondering what (in such an uncoordinated world) could account for the fact that a reasoner should recognize its validity.

This point generalizes to any information $I$ the possession of which could be argued to legitimize inferences which would not otherwise be normatively compelling: so long as the semantic relations between $I$ and the premises which it is supposed to connect are just as opaque as those between the unaided premises themselves, the possession of $I$ will just reduplicate the predicament which it was devised to overcome.

Let me mention a last possible response, one that, I think, is the best game in town for those who are particularly reluctant to construe of coordination as a semantical affair. Perhaps what creates the illusion that de jure co-reference should be construed as a semantic relation, is the mistaken presumption that the manifest-making feature which transforms opaquely valid arguments (such as CT) into transparently valid ones (like CC) be a further connecting proposition: i.e. the assumption that the notion of validity at issue in the logical appraisal of rational subjects be discriminative. This assumption of course does imply that, without the connecting proposition, the argument would be outright invalid. Perhaps this is the assumption that the hard referentialist ought to

Manuscrito-Rev. Int. Fil. Campinas, v. 41, n. 1, pp. 1-31, jan.-mar. 2018. 
resist.

Salmon (2012: 426) appears to approve of this line of thinking when he claims that "the raison d'etre of [the legitimating information] is not to render a non-manifest argument manifest - typically a mission impossible for correct information - but merely to supplement the premises that Fx and that Gx to open the reasoner's eyes to the recurrence of x". He goes on to argue that "Millians need not assume that the legitimizing information be simply a proposition - as opposed to, say, that which one knows (perhaps at least partially in a non-propositional manner) by virtue of recognizing someone or something, and of which one who fails to recognize is ignorant." (2012: 415). Along similar lines, Gerken 2012 has argued that the exercise of a "univocality competence" (without which reasoning would be impossible) determines normatively committing inferential presuppositions, which he construes of, however, as clearly distinguished from premise-beliefs and other tacit or standing attitudes. In particular, he argues, the reasoner needs not even be in possession of the concepts which would enable her to think this proposition, while still being in the position to use her univocality competence. On the ground of similar considerations, Taschek (1992) argued that the mistake consists in assuming that what the ignorant thinker lacks is some information at all.

Notice that, according to this position, one needs not deny that a proposition exists which expresses the legitimizing information (think of proposition P3*** above, for example). What is being denied is the further assumption that such proposition should make an invalid argument manifestly valid, when added as a premise to the argument. Indeed, notice that this is true also in the case of semantic understandings of coordination, including semantic relationism. If the tokens of "Cicero" in argument CC are semantically coordinated (DJCR), as they are intended to be, then there will be a proposition to the effect that this semantic fact obtains. However, this proposition (or the proposition that they simply co-refer, for that matter) needs not be appended to argument CC as an independent further premise, for CC to "become" manifestly valid. CC, we may suppose, unlike CT, is just plain (manifestly) valid unadorned as it is, relative to that coordination scheme. If this is a viable stance, i.e. if the legitimizing semantic coordination does not necessarily constitute a suppressed, manifest-making premise, why shouldn't the referentialist also be allowed to claim that some (non-semantic) correlating information legitimizes inferences, not as a further premise which makes them manifestly valid, but 
somehow directly, conferring a warrant to accept their conclusions given the premises?

In a nutshell, the present position consists in biting the bullet with respect to the objection that the notion of validity at issue is non discriminative. According to this proposal, it is not that TC is valid enthymematically: it is just plain valid. Only, some reasoners (those who would represent it as TC, for example) cannot see that it is valid, for they do not recognize the re-occurrence of the same individual in the two premises. While, as I said, I think this is the most plausible route that referentialists can take when it comes to explaining what distinguishes legitimately valid arguments from illegitimately valid ones, it can hardly be said to settle the issue. Here I will content myself with mentioning just two related concerns that I have about this move.

Firstly, I think it is suspicious if one's views of semantics have as a consequence that the distinction between enthymematic and valid arguments cannot be explained at the level of logic. If more than the truth of the premises is needed to derive the conclusion, one could argue, and the agent nonetheless "sees" that the argument is necessarily truth preserving, then the agent must be describable as reasoning enthymematically. But this, we have seen, is precisely what the present position denies.

Secondly, and relatedly, I think that this response raises some issues in the epistemology of logic. It is relatively uncontroversial that an act of thinking a sequence of propositions does not count as an act of deductive inference, on the sole ground that thinking the conclusion follows thinking the premises (in a temporal sequence). It is neither enough that thinking the conclusion be caused by thinking the premises. It is generally understood that the premises of a deductive inference must be connected to the conclusion in the right way. Whatever this "right way" is, I submit, it must be such that a reasoner who finds an inference compelling (for the right reasons) must also believe that the conclusion is supported by the premises. This belief, moreover, must be justified (and true): I may believe, wrongly, that the premises of an invalid argument support the conclusion, but this, by itself, does not make that argument valid. Now, what could possibly justify this belief, if the legitimizing information may even fail to be propositional in nature?

To see how this objection is supposed to work, suppose that an agent, call him Ludwig, were to believe that the conclusion of an inference like TC follows from the premises, without knowing (or believing) that "Cicero" co-refers with 
"Tully". Intuitively, we would say that Ludwig is merely conforming to the argument, but that his logical acumen is defective: his is a case of 'logical luck', as it were. ${ }^{17}$ But which part of his reasoning should the referentialist want to impeach? The argument, after all, is just plain (strictly) valid, and Ludwig believes that it is so (albeit for the wrong reasons). What's wrong with Ludwig's reasoning according to it? Not that his reasons are not really legitimating, for the present proposal is silent as to why the truly legitimating information is in fact legitimating. In particular, we said, the subject needs not even be aware of possessing this knowledge. So, how could poor Ludwig find out that his "knowledge" is not of the legitimating kind? Worse still, on what grounds are we to distinguish such illogical reasoners, the "conformers", from true rational agents?

Notice that, if manifest validity could be augmented by taking on board the thinkers' coordinating schemes, instead, then there would be a neat explanation for what's wrong with Ludwig's reasoning. Coordinated manifest validity, being epistemically transparent, is the only notion with respect to which rational thinkers can be required to be accountable for. Ludwig takes TC to be a valid argument when he should (and could) have known better. TC is not manifestly valid (relative to Ludwig's coordinating scheme), and this fact must be transparent to his mind.

\section{Conclusions}

If the notion of logical validity is to play its role in legitimizing the logical appraisal of rational subjects, I have argued, it must individuate a notion of implication that is more fine grained than either material or strict implication, for logical truths that are indistinguishable as to the modal profile of the propositions which they contain, may still be distinguishable as to whether they are (or not) transparently accessible to this or that rational subject. A notion of validity which does justice to the a-prioricity and normativity of logical truths

17 Sorensen (1998) and Faria (2009) have indeed argued that being rational can be a matter of luck. Although their views are interesting in their own right, they are of no consequence for the arguments put forward here, since these proceed from the conditional hypothesis that conforming to the basic principles of logic is constitutive of rationality.

Manuscrito - Rev. Int. Fil. Campinas, v. 41, n. 1, pp. 1-31, jan.-mar. 2018. 
must satisfy a stricter transparency requirement, one which is not insensitive to such distinctions in accessibility. I have argued that this desideratum can be made precise by requiring that validity be discriminative, viz. that it makes room for a distinction between valid inferences and enthymemes. I have discussed the prospects of formal, relevant and manifest validity as candidates for a notion which complies with this desideratum. The success, or failure, of these notions, however, was seen to hang on the viability of a semantical account of de jure co-reference.

What was said can be summarized as posing the following dilemma for the referentialist. Either accept that there is no notion of logical validity which makes logic normative for reasoning, thus jeopardizing our well entrenched practices of rational appraisal, as well as the very idea that logic is a domain of a priori truths; or accept that de jure co-reference is a semantical relation.

\section{References}

Almog, J. “Frege's Puzzles?” Journal of Philosophical Logic, 37 (6), 549-574, 2008. , Nichols, P. \& PePP, J. "A Unified Treatment of (Pro)Nominals in Ordinary English". In Bianchi, A. (ed.). On Reference. Oxford University Press, 2015.

Anderson, R. \& Belnap, N. "Enthymemes". Journal of Philosophy, 58 (23), 713- 723, 1961.

$\&$

Symbolic Logic, 27(1), 19-52, 1962. "The Pure Calculus of Entailment". Journal of

Boghossian, P. "The Transparency of Mental Content". Philosophical Perspectives, 8, 33-50, 1994.

Campbell, J. "Is Sense Transparent?" Proceedings of the Aristotelian Society, 88, 273-292, 1987.

DiCKIE, I. \& RATTAN, G. "Sense, Communication, and Rational Engagement". Dialectica, 64, 131-51, 2010.

FARIA, P. Unsafe reasoning: a survey. Doispontos. 6 (2), 185-20, 2009.

FAUCONNIER, G. La coréference: Syntaxe ou sémantique? Paris: Seuil, 1974. 
FIEngo, R., \& MAY, R. "De Lingua Belief'. Cambridge, Massachusetts: Bradford, 2006.

FINE, K. Semantic Relationism. (SR) Oxford: Blackwell, 2007. “Recurrence: A rejoinder". Philosopbical Studies, 169(3), 425-428, 2014.

FREGE, G. 'Über Funktion und Begriff'. Translated and reprinted in Beaney, M. (Ed.) (1997), The Frege Reader. Oxford: Basil Blackwell, 1891.

"Über Sinn und Bedeutung (SuB)". Translated and reprinted in Beaney, M. (Ed.) (1997), The Frege Reader. Oxford: Basil Blackwell, 1892.

GERKEN, M. "Univocal Reasoning and Inferential Presuppositions". Mikkel Gerken, Erkenn, 76, 373-394, 2012.

GIBBARD, A. Meaning and Normativity. Oxford: Oxford University Press, 2012.

Goodsell, T. "Is De Jure Coreference Non-Transitive?” Philosophical Studies, 167, 291-312, 2014.

Glezakos, S. “Can Frege pose Frege's Puzzle?” In Joseph Almog \& Paolo Leonardi (Eds.), The Philosophy of David Kaplan. Oxford: Oxford University Press, 2009.

KAPLAN, D. "Afterthoughts". In J. Almog, H. Wettstein and J. Perry (eds.), Themes from Kaplan, pp. 565-614. New York: Oxford University Press, 1989.

KRIPKE, S. "A Puzzle About Belief'. In Nathan Salmon and Scott Soames (eds.) 1988: Propositions and Attitudes, pp. 102-148. New York: Oxford University Press, 1979.

LAWLOR, K. "Varieties of Co-reference", Philosophy and Phenomenological Research, 81(2), pp. 485-495, 2010.

LEWIS, C. I. "Implication and the Algebra of Logic". Mind, 21, pp. 522-531, 1912.

Macfarlane, J. "In What Sense (if any) is Logic Normative for Thought?" Unpublished manuscript, 2004.

NeALE, S. "Pragmatism and Binding". In Z. Szabo (ed.) Semantics versus Manuscrito-Rev. Int. Fil. Campinas, v. 41, n. 1, pp. 1-31, jan.-mar. 2018. 
Pragmatics, pp. 165-285. Oxford: Clarendon Press, 2005.

PERRY, J. Reference and Reflexivity, 2nd Edition. Stanford: CSLI, 2012.

PINILlos, A. "Coreference and meaning". Philosophical Studies, 154 (2), pp. 301324, 2011.

QuINE, W. "From a Logical Point of View". Cambridge, Mass.: Harvard University Press; revised edition, 1980. 1953.

"Methods of Logic". Cambridge, Mass.: Harvard University Press; revised edition, 1980. 1950.

ReCanati, F. Mental Files. Oxford University Press, Oxford, 2012.

SAlmon, N. "Frege's Puzzle". Ridgeview, 1986.

“Recurrence". Philosophical Studies, 159, pp. 407-441, 2012.

SHAPIRO, S. "Logical Consequence, Proof Theory, and Model Theory". In The Oxford Handbook of Philosophy of Mathematics and Logic. Oxford University Press, pp. 651- 670, 2005.

SOREnSEn, A. "Logical Luck". Philosophical Quarterly, 48 (192), pp. 319-334, 1998.

StRawson, P. "Propositions, Concepts and Logical Truths". The Philosophical Quarterly, 7(26), pp. 15-25, 1957.

TAscheK, W. "Frege's Puzzle, Sense, and Information Content". Mind, New Series, 101(404), pp.767-791, 1992.

TAYLOR, K. Reference and the Rational Mind. Stanford, Calif.: CSLI, 2003.

WEIsS, M. "A Closer Look at Manifest Consequence". Journal of Philosophical Logic, 43(2-3), pp. 471-498, 2014.

Wettstein, H. "Has Semantics Rested on a Mistake?” The Journal of Philosophy, 83(4), 185-209, 1986.

\section{$(\mathrm{cc}) \mathrm{Br}$}

Manuscrito - Rev. Int. Fil. Campinas, v. 41, n. 1, pp. 1-31, jan.-mar. 2018. 